\title{
СРАВНИТЕЛЬНЫЙ АНАЛИЗ ТЕРМИНОВ ДВУХ ИЗДАНИЙ МЕЖДУНАРОДНОЙ АНАТОМИЧЕСКОЙ НОМЕНКЛАТУРЫ
}

\author{
Костромина T.A. \\ Маркова Н.И.
}

Курский государственный медицинский университет

\begin{abstract}
Аннотация: Данная статья сфокусирована на описании результатов сравнительного анализа терминов, включенных в Международную анатомическую номенклатуру с версией на русском языке, изданную в 1980 году под редакцией С.С. Михайлова (Parisiana Nomina Anatomica - PNA) и терминов, включенных в Международную анатомическую терминологию 2003 года издания под редакцией Л.Л. Колесникова (Terminologia Anatomica - TA). В статье дана историческая справка об эволюции формирования международной анатомической номенклатуры и роли латинского языка в становлении номенклатур на национальных языках.
\end{abstract}

Объектом структурно-семантического сравнительного анализа стал раздел «Regiones et partes corporis - области и части тела» (1980), а в номенклатуре 2003г. издания соответствующий ему раздел - «Plana, lineae et regiones - плоскости, линии и области».

В результате исследования выявлены:

- термины, удаленные из перечня PNA как устаревшие;

- термины, добавленные в ТА, что является подтверждением неразрывной связи между эволюционными процессами в науке и развитием терминологической системы;

- термины, в которых произошли словообразовательные изменения на уровне лексических единиц и грамматической формы номенклатурных наименований.

Ключевые слова: Международная анатомическая номенклатура; латинский язык; сравнительный структурно-семантический анализ; раздел Regiones et partes corporis - Области и части тела. 


\title{
COMPARATIVE ANALYSIS OF THE TERMS OF TWO EDITIONS OF THE INTERNATIONAL ANATOMICAL NOMENCLATURE
}

\section{Kostromina T.A. Markova N.I.}

\begin{abstract}
This article is focused on describing the results of a comparative analysis of terms included in the International Anatomical Nomenclature with a version in Russian, published in 1980 under the editorship of S.S. Mikhailov (Parisiana Nomina Anatomica - PNA) and terms included in the International Anatomical Terminology edited by L.L. Kolesnikov (Terminologia Anatomica -TA) in 2003. The article provides a historical background on the evolution of the formation of the international anatomical nomenclature and the role of the Latin language in the formation of nomenclatures in national languages.
\end{abstract}

The object of structural-semantic comparative analysis was the section «Regiones et partes corporis - areas and parts of the body» (1980), and in the 2003 edition the corresponding section is - «Plana, lineae et regiones - planes, lines and regions».

The study revealed:

- terms removed from the PNA listing as obsolete;

- terms added to TA, which is a confirmation of the inextricable connection between evolutionary processes in science and the development of the terminological system;

- terms in which word-formation changes have occurred at the level of lexical units and grammatical form of nomenclature names.

Key words: International Anatomical Nomenclature; historical background; Latin language; comparative structural and semantic analysis; section Regiones et partes corporis - Areas and parts of the body

Как известно, анатомическая терминология складывалась в течение многих веков на основе двух классических языков: древнегреческого и латинского. Современная Международная анатомическая терминология состоит преимущественно из латинских и латинизированных слов.

Анатомическая номенклатура постоянно пополнялась в течение веков. Каждое открытие в области анатомии обогащало ее новым названием. Нередко 
одни и те же органы в разных странах получали различные наименования; на международном уровне появилось большое количество синонимов, что стало причиной многих ошибок. Благодаря тому, что латинский язык был признан международным эталоном для обозначения органов и частей тела человека, анатомическая терминология стала «интернациональным мостиком» в сфере медицины.

В 1955 г. на VI Международном конгрессе анатомов в Париже была принята Международная анатомическая номенклатура на латинском языке, которая на последующих международных конгрессах была дополнена и исправлена. Было рекомендовано создать национальные анатомические номенклатуры, соответствующие Парижской международной номенклатуре.

Этот список был утвержден как первый в истории науки перечень анатомических терминов, получивший официальное международное признание как Парижская анатомическая номенклатура (PNA) [1]. Следующий, VII Интернациональный конгресс анатомов, проходивший в Нью-Йорке в 1960 г., утвердил дополнения и поправки к PNA.

В 1965 г на VIII Интернациональном конгрессе анатомов в Висбадене (ФРГ) было принято около тысячи поправок, внесенных в список Nomina anatomica. некоторые термины были исключены. PNA охватывает около 6000 наименований.

В течение многих лет анатомическая номенклатура стремительно видоизменялась, теряя устаревшие, неактуальные термины и приобретая новые.

В настоящее время используется анатомическая терминология под редакцией Л.Л. Колесникова Terminologia anatomica - TA [2].

Для взаимодействия филологов, врачей и фармацевтов из разных стран необходима общая актуальная номенклатура, которая должна быть удобной и доступной для специалистов разных поколений.

Поскольку дисциплина «Анатомия человека» изучается на базе Международной анатомической номенклатуры, становится очевидной важность интеграции работы кафедры анатомии человека и кафедры латинского языка и основ терминологии.

Хорошее знание латинского языка помогает в освоении одной из базовых дисциплин в медицинском образовании - Анатомии человека. В 2003 году с выходом в свет переработанного издания Международной анатомической терминологии кафедра латинского языка и основ терминологии КГМУ поставила перед собой задачу провести структурно-семантический 
сравнительный анализ двух международных номенклатур: Parisiana Nomĭna Anatomǐca (1955 г.) и Terminologia anatomica (2003 г.).

Мы провели сравнительный структурно-семантический анализ терминов раздела, описывающего области и части тела в двух выше обозначенных изданиях.

В международной анатомической номенклатуре 1980г. этот раздел назывался Regiones et partes corporis - области и части тела, а в номенклатуре 2003г. издания - Plana, lineae et regiones - плоскости, линии и области. Такие термины как plana frontalia - фронтальные плоскости; plana coronalia венечные плоскости; plana horizontalia - горизонтальные плоскости; plana transversalia - поперечные плоскости; plana sagittalia - сагиттальные плоскости; plana paramediana - парамедианные плоскости, околосрединные плоскости; planum medianum - срединная плоскость - появились в издании 2003 года, тогда как в номенклатуре 1980 года издания их не было.

Термин planum transpyloricum в 1980 году имел перевод чреспилорическая плоскость, а в издании 2003года транспилорическая плоскость. Такие термины как linea preaxillaris - предподмышечная линия; linea postaxillaris - послеподмышечная линия не вошли в издание 2003 года.

Что касается раздела области головы - Regiones capitis, то в издании 2003 года появились термины regio auricularis - область ушной раковины и regio mastoidea - область сосцевидного отростка. Анализируя раздел «Область лица» - Regio faciei, мы установили, что в издании 1980 года термин «область» стоит во множественном числе - regiones, а в издании 2003 в единственном числе regio. Термины sulcus suprapalpebralis - борозда верхнего века u sulcus infrapalpebralis - борозда нижнего века; Regio parotideomasseterica околоушно-жевательная область; sulcus nasolabialis - носогубная борозда; sulcus mentolabialis - подбородочно - губная борозда появились только в издании 2003 года.

В разделе «Области шеи» - Regiones cervicales, В латинском языке cervicales имя прилагательное - согласованное определение, стоящее во множественном числе, тогда как в русском эквиваленте - это существительное в родительном падеже, то есть, несогласованное определение. Остальные термины этого раздела полностью совпадают в обеих номенклатурах.

Раздел «Области груди» - Regiones pectorales - приведено в номенклатуре 1980 года, в терминологии 2003 года этот раздел называется Regiones thoracicae anteriores et laterals - Передние и латеральные области груди. В данном разделе 
в новой номенклатуре добавлен один термин: regio pectoralis lateralis латеральная область груди.

Раздел «Области спины» - Regiones dorsales - имел такое название в номенклатуре 1980г., но в новой номенклатуре называется Regiones dorsales, regiones dorsi - области спины. В этот раздел добавлены следующие термины: foveola coccygea - копчиковая ямочка; trigonum lumbale inferius - нижний поясничный треугольник; trigonum lumbale superius - верхний поясничный треугольник. А термина trigonum lumbale - поясничный треугольник в новой номенклатуре уже нет.

В разделе «Область промежности» - Regio perinealis - изменений не наблюдается. В разделе «Области верхней конечности»-Regiones membri superioris - в некоторых терминах добавлено понятие область(regio).

Сравним: 1980 год: cubitus - локоть; antebrachium - предплечье; manus кисть; сагриs - запястье; теtacarpus - пясть; pes - cmona.

2003 год: regio cubitalis - область локтя, локтевая область; regio antebrachialis - область предплечья; regio тапиs - область кисти; regio carpalis - область запястья; regio metacarpalis - пясть; regio pedis - область cmonbl. Причем в русском переводе это существительные, а в латинском термине - прилагательные, кроме «manus» и «pedis».Кроме этого, в данном разделе термин palma manus - ладонь кисти заменен на palma, vola, regio palmaris - ладонь, ладонная область.

В издании 2003 года в этот раздел добавлены следующие термины: regio retromalleolaris lateralis - латеральная позадилодыжечная область; regio retromalleolaris medialis - медиальная позадилодыжечная область; arcus pedis longitudinalis - продольный свод стопы; pars lateralis - латеральная часть; pars medialis- медиальная часть; arcus pedis transversus proximalis - проксимальный поперечный свод стопы; arcus pedis transversus distalis - дистальный поперечный свод стопы; facies plantaris digitorum - подошвенные поверхности пальцев; facies dorsalis digitorum - тыльные поверхности пальцев.

Таким образом, при сопоставлении двух номенклатур мы пришли к следующим выводам:

- выявлены термины, удаленные из перечня PNA как устаревшие;

- выявлены термины, добавленные в ТА, что является подтверждением неразрывной связи между эволюционными процессами в науке и развитием терминологической системы; 
- выявлены термины, в которых произошли словообразовательные изменения на уровне лексических единиц и грамматической формы номенклатурных наименований.

\section{Список литературы}

1. Nomina anatomica. Международная анатомическая номенклатура / Под ред. С.С. Михайлова. - издание четвертое, переработанное и дополненное / М.: Медицина, 1980.

2. Terminologia anatomica. Международная анатомическая номенклатура (с официальным списком русских эквивалентов) / Под ред. Колесникова Л.Л. / М.: Медицина, 2003. 